\title{
Efficacy of Plerixafor for Peripheral Stem Cell Mobilisation in Autologous Transplantation: A Single Centre Study
}

\author{
Kiran Pura Krishnamurthy ${ }^{1 *}$, D. V. Ganesha², Girish Badarkhe3 ${ }^{3}$, Diganta Hazarika4, \\ Radheshyam Naik ${ }^{1}$
}

${ }^{1}$ Department of Medical Oncology, HealthCare Global Enterprises Ltd., Bangalore, India

${ }^{2}$ Department of Medical Oncology, St John's Medical College Hospital, Bangalore, India

${ }^{3}$ Department of Hematology, Healthcare Global Enterprises Ltd., Bangalore, India

${ }^{4}$ Department of Pathology, Healthcare Global Enterprises Ltd., Bangalore, India

Email: *drkiranpk265@gmail.com

How to cite this paper: Krishnamurthy, K.P., Ganesha, D.V., Badarkhe, G., Hazarika, D. and Naik, R. (2020) Efficacy of Plerixafor for Peripheral Stem Cell Mobilisation in Autologous Transplantation: A Single Centre Study. Journal of Cancer Therapy, 11, 483-490.

https://doi.org/10.4236/jct.2020.118041

Received: June 24, 2020

Accepted: August 15, 2020

Published: August 18, 2020

Copyright $\odot 2020$ by author(s) and Scientific Research Publishing Inc. This work is licensed under the Creative Commons Attribution International License (CC BY 4.0).

http://creativecommons.org/licenses/by/4.0/

\begin{abstract}
Plerixafor is a stem cell mobilising agent, and when administered along with G-CSF has been shown to improve CD34+ stem cell collections in lymphoma and multiple myeloma patients compared to G-CSF alone. Patients who failed to mobilize $<2.0 \times 10^{6}$ cells $/ \mathrm{kg}$ on Day 1 collection received Plerixafor and G CSF for further collections. Study population was divided into two groups as plerixafor yes (PY) who are poor mobilizers and Plerixafor No (PN) who are good mobilizers. Out of 49 patients, 28 patients were in PY group and 21 patients in PN group. Median value of apheresis CD34 of day 1 was 1.75 (range 0.258 to 8.52 ) in PY group and 2.63 (range 1.06 to 6.29) in PN group and that of day 2 was 3.845 (range 0.317 to 13.89) in PY group and 3.18 (range 0.88 to 6.348) in PN group. Median value of total apheresis CD34 was 8.10 (range 4.33 to 18.66 ) in PY group and 7.58 (range 4.06 to 9.8) in PN group. Median day of neutrophil engraftment was 11.5 (range 9 - 22) in PY group and 11 (range 9 - 36) in PN group whereas median day of platelet engraftment was 14 (range 9 - 98) in PY group and 13 (range 11 - 98) in PN group. It can be concluded that the use of plerixafor not only enabled poor mobilizers of Lymphoma and Multiple Myeloma to collect adequate stem cells to proceed to ASCT, but also had early neutrophil and platelet engraftment which was comparable with good mobilizers.
\end{abstract}

\section{Keywords}

Plerixafor, Poor Mobilizers, ASCT 


\section{Introduction}

Plerixafor is a stem cell mobilising agent approved for use along with G-CSF in lymphoma and multiple myeloma patients whose cells mobilize poorly from bone marrow [1]. The most important risk factor for inadequate mobilization is prior chemotherapy that received especially those toxic to stem cells such as high dose cyclophosphamide $\left(>7.5 \mathrm{~g} / \mathrm{m}^{2}\right)$, melphalan, carmustine, procarbazine, fludarabine, nitrogen mustard and chlorambucil. The other risk factors for poor mobilisation are listed in Table 1.

Plerixafor is a CXCR4 receptor antagonist that reversibly inhibits the interaction between CXCR4 and SDF-1 $\alpha$ [4] [5] [6] [7]. Interruption of the receptor-ligand interaction results in mobilization of CD34 hematopoietic stem cells to peripheral blood from bone marrow where they can be collected by leukapheresis. Plerixafor when administered along with G-CSF has shown to improve CD34+ stem cell collections in lymphoma and multiple myeloma patients [8] [9]. Plerixafor is administered as a subcutaneous injection at a recommended dose of $0.24 \mathrm{mg} / \mathrm{kg}$ which results in sustained increase in circulating CD34+ cells. Dose adjustments are not needed for patients with hepatic or renal insufficiency and are well tolerated [10].

Combination of plerixafor and G-CSF minimizes the requirement of remobilization, allowing patients to proceed to transplantation with adequate stem cell yield. There is no proper definition of a poor mobilizer, but commonly used parameters like peripheral blood CD34+ stem cell count and stem-cell yield on the 1st day of leukapheresis are quite acceptable. Adding plerixafor to G-CSF for initial mobilization therapy can be considered regardless of the underlying malignancy [e.g. plasma cell dyscrasias (myeloma, amyloidosis), Non-Hodgkins lymphoma (NHL), Hodgkin lymphoma (HL) and germ-cell tumors]. For patients with low peripheral blood CD34+ count (for example, 10/ $\mu \mathrm{L}$ ) before stem-cell harvesting or with an inadequate first day leukapheresis, it is recommended that plerixafor be added to the mobilization regimen to increase stem-cell collection and prevent need for remobilization [10].

Table 1. Risk factors and characteristics associated with poor autologous stem cell mobilization [2] [3].

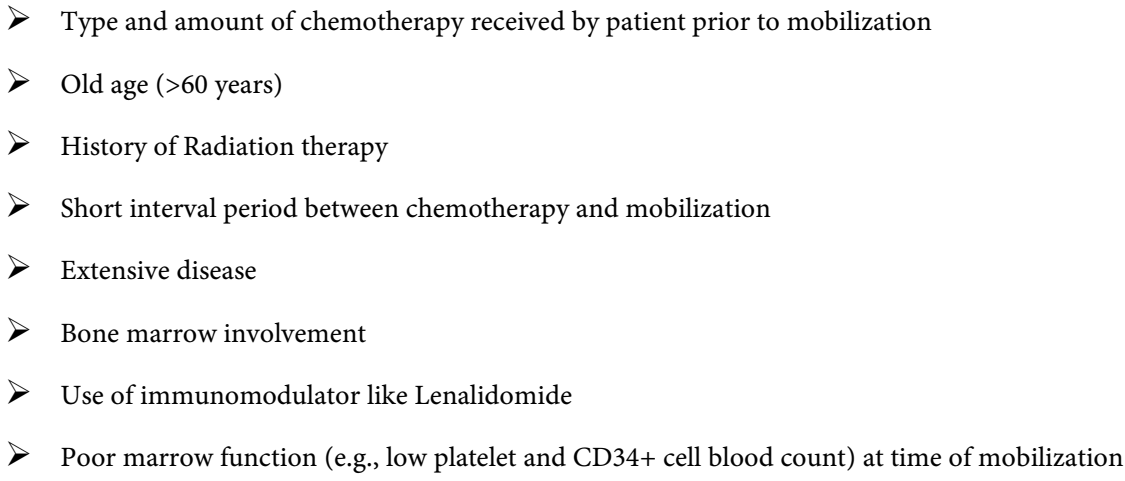




\section{Material and Methods}

Our study was done at HCG hospital Bangalore which is a tertiary care oncology centre.

Inclusion criteria: 1) Patients aged between 18 - 68 years; 2) Patients undergoing ASCT for multiple myeloma and lymphoma and 3) Patients received $\leq 3$ lines of induction chemotherapy.

Exclusion criteria: 1) Patients aged $<18$ years or $>68$ years; 2) Patients undergoing ASCT for other indications.

A total of 49 patients undergoing stem cell transplantation for hematological malignancies during the period of June 2016 to May 2018 were included after prior informed consent. The benefit of adding plerixafor to G-CSF as rescue during mobilization in poor mobilizers was analyzed. Of forty nine study population, twenty eight patients received plerixafor along with G-CSF after Day 1 collection due to poor yield. Twenty one patients whose stem cell mobilization was good received only G-CSF. Apheresis CD34 counts of $<2.0 \times 10^{6}$ cells $/ \mathrm{kg}$ were taken as cutoff. Patients who failed to mobilize this cut off value on Day 1 collection received Plerixafor and G-CSF for further collection. Study population was divided into two groups as plerixafor yes (PY) who were poor mobilizers and Plerixafor No (PN) who were good mobilizers. Median values of apheresis on day 1 CD34 count, day 2 CD34 count was calculated and analyzed in the PY and PN groups. Median values of Neutrophil and platelet engraftment were also compared between PY and PN groups. Major factors responsible for poor mobilization like age, comorbidities and previous lines of chemotherapy received were studied between the two groups. Chi-square test was used to find association between categorical variables. $\mathrm{P}$ value $<0.05$ was considered significant. Apheresis CD34 cells were expressed as no of cell $\times 10^{6}$ cells $/ \mathrm{kg}$. Our study was approved by the Institutional Ethics Committee of Healthcare global enterprises limited.

\section{Results}

Forty-nine patients diagnosed to have multiple myeloma or Lymphoma who were in remission and required autologous peripheral blood stem cell transplant (ASCT) were enrolled in our study and their data was analyzed. Baseline characteristics are listed in Table 2. Out of the forty-nine patients, 26 (53\%) were male and $23(47 \%)$ were female. The median age was $50(18-68)$ years. Twenty six patients were diagnosed as multiple myeloma and the remaining twenty three as lymphoma. Of the 23 lymphoma patients, 12 were of diffuse large B cell lymphoma (DLBCL) type, Hodgkin lymphoma (HL) constituted 7, 3 had $\mathrm{T}$ cell lymphoma and 1 patient was of Mantle cell lymphoma. $57.1 \%$ of the study group were Good mobilizers (PN) where plerixafor was not used and $42.9 \%$ of the study group were poor mobilizers (PY) who received plerixafor. The median age of patients in PY group was 49.5 (19 - 68) which is lesser than the median age of patients in PN group 53 (18 - 67). Out of 31 patients who received one line of 
Table 2. Baseline characteristics (data are represented as median, range and percentage).

\begin{tabular}{cc}
\hline Baseline Parameters & N \\
\hline Median Age (range) & $50(18-68)$ \\
Gender (\%) & $26(53 \%)$ \\
Male & $23(47 \%)$ \\
Female & \\
Co-morbidities (\%) & $7(14.3 \%)$ \\
Diabetes Mellitus & $5(10.2 \%)$ \\
Hypertension & $3(6.1 \%)$ \\
Hypothyroidism & $1(2 \%)$ \\
HBSAg + ve & $1(2 \%)$ \\
HIV + ve & $1(2 \%)$ \\
Polio LL & \\
Single Line & $31(63.3 \%)$ \\
Multiple Line & $18(36.7 \%)$ \\
Poor Mobilizers (\%) & $28(57.1 \%)$ \\
Good Mobilizers (\%) & $21(42.9 \%)$ \\
\hline
\end{tabular}

chemotherapy, 16 patients (51.6\%) were in PY group and 15 (48.4\%) in the PN group. Out of 18 patients who received multiple lines of chemotherapy, 12 patients (66.6\%) were in PY group and 6 patients (33.3\%) in the PN group. Average leukapheresis per person was 2.64 in PY group and 2.47 in the PN group. Median value of apheresis CD34 count on day 1 was 1.75 (range $0.258-8.52$ ) in PY group and 2.63 (range $1.06-6.29$ ) in the PN group. Day 2 collection of stem cells was 3.845 (range 0.317 - 13.89) in PY group and 3.18 (range 0.88 - 6.348) in the PN group. Median value of total apheresis CD34 was 7.56 (3.55 - 18.19) in PY group and $7.5(3.17$ - 10.73) in the PN group which is almost the same (Table 3). Median day of neutrophil engraftment was 11.5 (range 9 - 22) in PY group and 11 (range 9 - 36) in the PN group whereas median day of platelet engraftment was 14 (range 9 - 98) in PY group and 13 (range 11 - 98) in the PN group (Figure 1).

\section{Discussion}

Plerixafor is a novel agent approved for use in conjunction with G-CSF during Autologous stem cell transplant in lymphoma and multiple myeloma for poor mobilizers [1]. The current regimen for mobilization of stem cells with granulocyte colony-stimulating factor (G-CSF), alone or in combination with chemotherapy fails in $10 \%-25 \%$ of patients. In a single institution study by Chitra et al. [11] advanced age ( $>60$ years) was one of the important factors responsible for poor mobilization. It was reported that prior lines of treatment received also 


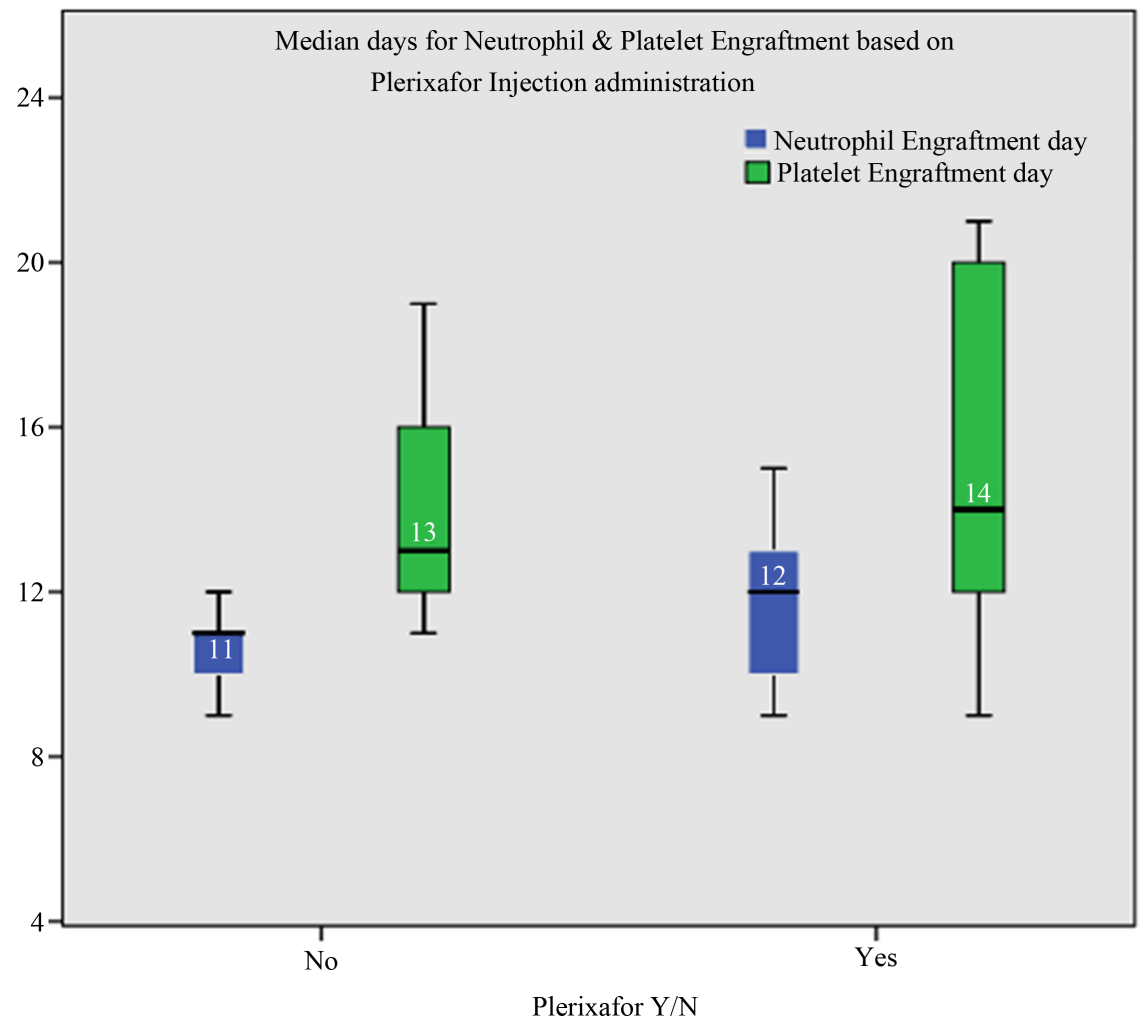

Figure 1. Median days of neutrophil and platelet engraftment in PY and PN group. PY-Plerixafor group, PN-Plerixafor no group (good mobilizers).

Table 3. Comparison between PY and PN group (data are represented as median, range and percentage).

\begin{tabular}{ccc}
\hline Parameters & $\begin{array}{c}\text { Plerixafor Group (PY) } \\
(\mathrm{N}=28)\end{array}$ & $\begin{array}{c}\text { Good Mobilizers (PN) } \\
(\mathrm{N}=21)\end{array}$ \\
\hline No. of Collection (Mean) & $2.64 \pm 0.48$ & $2.47 \pm 0.5$ \\
Median Age (range) & $49.5(19-68)$ & $53(18-67)$ \\
Gender (\%) & & $11(52.4 \%)$ \\
Male & $13(46.4 \%)$ & $10(47.6 \%)$ \\
Female & $15(53.6 \%)$ & $15(71.4 \%)$ \\
Induction Chemotherapy (\%) & & $6(28.6 \%)$ \\
Single Line & $16(57.1 \%)$ & \\
Multiple Line & $12(42.9 \%)$ & $2.63(1.06-6.29)$ \\
Apheresis (Median) & & $3.18(0.88-6.348)$ \\
D1 & $1.755(0.258-8.52)$ & $1.61(0.89-3.11)$ \\
D2 & $3.845(0.317-13.89)$ & $13(11-98)$ \\
D3 & $2.28(0.24-12.29)$ & $7.5(3.17-10.73)$ \\
Total & $7.56(3.55-18.19)$ & $11(96)$ \\
Platelet engraftment (Median) & $11.5(9-22)$ & $14(9-98)$ \\
\hline
\end{tabular}


adversely impact mobilization and is one of the major risk factor for poor mobilization. Similarly, a study by A Olivieri et al. showed that more than 2 lines of chemotherapy received prior to stem cell collection is an important criteria in identifying poor mobilizers [12]. In our study we found no significance with age and prior line of induction chemotherapy in poor mobilizers, in fact we found lesser median age in poor mobilizers (49.5 years) than good mobilizers (53). Irrespective of age and number of line of induction chemotherapy, plerixafor has given equal results of apheresis (7.56 vs 7.5), platelet engraftment (14 vs 13) and neutrophil engraftment (11.5 vs 11 ) as compared to good mobilizers (Figure 1). This data shows the significance of plerixafor efficacy in poor mobilizers irrespective of factors such as age and prior lines of chemotherapy. Our study is similar to a study by Varmavuo et al. where the median number of collected CD34+ cells was $3.5 \times 10^{6} \mathrm{CD} 34+$ cells $/ \mathrm{kg}$ in plerixafor group and $4.2 \times 10^{6} \mathrm{CD} 34+$ cells/kg in the control group. $(\mathrm{p}=0.076)$. Engraftment was also comparable between the two groups (10 days for neutrophils and 14 days for platelets, respectively) [13]. Average leucapheresis per person of 2.64 was achieved in PY group after adding plerixafor which was comparable to 2.47 in the PN group. A multi centre time motion analysis of plerixafor in poor mobilizers of non Hodgkins lymphoma patients showed that poor mobilizers who received plerixafor had a decrease in apheresis sessions and thereby costs [14]. Median value of apheresis CD34 count on day 1 was 1.75 in PY group and 2.63 in the PN group. Patients in PY group received plerixafor along with G CSF after day 1 collection. When median value of day 2 was analysed there was 2.19 times increase in apheresis CD34 counts in PY group (3.845) as compared to day 1. In PN group, those who required only G-CSF for stem cell mobilisation, had 1.20 times increase in CD34 count and median value on day 2 was 3.18. Median values of total CD34 were 7.56 in PY group and 7.5 in the PN group. This shows that PY group which represented poor mobilizers had comparable stem cell collection than PN group post plerixafor administration. Our study was comparable to a double blind study by DiPersio et al. where use of plerixafor resulted in a median of 4.8 -fold increase in peripheral blood CD34 cell count compared to only a 1.7 -fold increase with G-CSF alone. It also showed that regimen of plerixafor and G-CSF resulted in a statistically significantly higher probability of achieving optimal CD34 cell target for tandem transplantation requiring fewer apheresis procedures compared with placebo and G-CSF [15]. In a study done by Basak et al, the minimum target of $>2.0 \times 10^{6} \mathrm{CD} 34+$ cells/kg body weight was achieved in $12 / 16$ patients $(75 \%)$ with a median of 2 leukapheresis (range, $1-3$ ) in the plerixafor added group. They concluded that plerixafor is an efficient and useful agent for stem cell mobilization in myeloma and lymphoma patients who have failed previous mobilization attempts [16]. These findings indicated that plerixafor mobilized stem cells are of good quality and can result in early engraftment which in turn leads to improved survival. Malik et al. also showed that engraftment and outcomes after ASCT are comparable in lymphoma and myeloma patients receiving plerixafor as compared to chemomobilized patients without use 
of plerixafor [17].

Limitation of our study is the small sample size.

\section{Conclusion}

Plerixafor is beneficial for mobilizing an adequate number of stem cells when used along with G-CSF during autologous stem cell transplantation. Prior lines of chemotherapy received are an important factor for poor mobilization in our study. The use of plerixafor not only enabled poor mobilizers of lymphoma and multiple myeloma to collect adequate stem cells for ASCT, but also had early neutrophil and platelet engraftment which was comparable to good mobilizers. Large volume studies are needed to determine the association between comorbidities and poor mobilization.

\section{Ethics}

The study was approved by the Institutional Ethics Committee.

\section{Conflicts of Interest}

The authors declare no conflict of interest.

\section{References}

[1] Mozobil, R. (2009) Summary of Product Characteristics. Genzyme Europe B.V., Naarden.

[2] Shea, T.C. and DiPersio, J.F. (2009) Mobilization of Autologous Peripheral Blood Hematopoietic Cells for Cellular Therapy. In: Applebaum, F.R., Forman, S.J., Negrin, R.S. and Blume, K.G., Eds., Thomas' Hematopoietic Cell Transplantation, Wiley-Blackwell, Hoboken, 590-604. https://doi.org/10.1002/9781444303537.ch41

[3] Bensinger, W., Appelbaum, F., Rowley, S., et al. (1995) Factors That Influence Collection and Engraftment of Autologous Peripheral-Blood Stem Cells. Journal of Clinical Oncology, 13, 2547-2555.

[4] Martin, C., Bridger, G.J. and Rankin, S.M. (2006) Structural Analogues of AMD3100 Mobilise Haematopoietic Progenitor Cells from Bone Marrow in Vivo According to Their Ability to Inhibit CXCL12 Binding to CXCR4 in Vitro. British Journal of Haematology, 134, 326-329. https://doi.org/10.1111/j.1365-2141.2006.06181.x

[5] Hatse, S., Princen, K., Bridger, G., De Clercq, E. and Schols, D. (2002) Chemokine Receptor Inhibition by AMD3100 Is Strictly Confined to CXCR4. FEBS Letters, 527, 255-262. https://doi.org/10.1016/S0014-5793(02)03143-5

[6] Fricker, S.P., Anastassov, V., Cox, J., et al. (2006) Characterization of the Molecular Pharmacology of AMD3100: A Specific Antagonist of the G-Protein Coupled Chemokine Receptor, CXCR4. Biochemical Pharmacology, 72, 588-596. https://doi.org/10.1016/j.bcp.2006.05.010

[7] Gerlach, L.O., Skerlj, R.T., Bridger, G.J. and Schwartz, T.W. (2001) Molecular Interactions of Cyclam and Bicyclam Non-Peptide Antagonists with the CXCR4 Chemokine Receptor. The Journal of Biological Chemistry, 276, 14153-14160. https://doi.org/10.1074/jbc.M010429200

[8] Devine, S.M., Flomenberg, N., Vesole, D.H., et al. (2004) Rapid Mobilization of CD34+ Cells Following Administration of the CXCR4 Antagonist AMD3100 to Pa- 
tients with Multiple Myeloma and Non-Hodgkin's Lymphoma. Journal of Clinical Oncology, 22, 1095-1102. https://doi.org/10.1200/JCO.2004.07.131

[9] Flomenberg, N., Devine, S.M., Dipersio, J.F., et al. (2005) The Use of AMD3100 plus G-CSF for Autologous Hematopoietic Progenitor Cell Mobilization Is Superior to G-CSF Alone. Blood, 106, 1867-1874. https://doi.org/10.1182/blood-2005-02-0468

[10] Kouroukis, C., Varela, N., Bredeson, C., Kuruvilla, J. and Xenocostas, A. (2016) Plerixafor for Autologous Stem-Cell Mobilization and Transplantation for Patients in Ontario. Current Oncology, 23, 409. https://doi.org/10.3747/co.23.3137

[11] Hosing, C., Saliba, R.M., Ahlawat, S., Körbling, M., Kebriaei, P., Alousi, A., De Lima, M., Okoroji, J.G., McMannis, J., Qazilbash, M. and Anderlini, P. (2009) Poor Hematopoietic Stem Cell Mobilizers: A Single Institution Study of Incidence and Risk Factors in Patients with Recurrent or Relapsed Lymphoma. American Journal of Hematology, 84, 335-337. https://doi.org/10.1002/ajh.21400

[12] Olivieri, A., Marchetti, M., Lemoli, R., Tarella, C., Iacone, A., Lanza, F., Rambaldi, A. and Bosi, A. (2012) Proposed Definition of "Poor Mobilizer" in Lymphoma and Multiple Myeloma: An Analytic Hierarchy Process by Ad Hoc Working Group Gruppo ItalianoTrapianto di Midollo Osseo. Bone Marrow Transplantation, 47, 342-351. https://doi.org/10.1038/bmt.2011.82

[13] Varmavuo, V., Rimpiläinen, J., Kuitunen, H., Nihtinen, A., Vasala, K., Mikkola, M., Kutila, A., Lehtonen, P., Kuittinen, T., Mäntymaa, P. and Nousiainen, T. (2014) Engraftment and Outcome after Autologous Stem Cell Transplantation in Plerixafor-Mobilized Non-Hodgkin's Lymphoma Patients. Transfusion, 54, 1243-1250. https://doi.org/10.1111/trf.12434

[14] Mohty, M., Azar, N., Chabannon, C., Le Gouill, S., Karlin, L., Farina, L., Milkovich, G., Ostermann, H., Glaß, B., Noppeney, R. and Kron, F. (2018) Plerixafor in Poor Mobilizers with Non-Hodgkin's Lymphoma: A Multi-Center Time-Motion Analysis. Bone Marrow Transplantation, 53, 246-254.

https://doi.org/10.1038/s41409-017-0033-0

[15] DiPersio, J., Stadtmauer, E., Nademanee, A., et al. (2009) Plerixafor and G-CSF versus Placebo and G-CSF to Mobilize Hematopoietic Stem Cells for Autologous Stem Cell Transplantation in Patients with Multiple Myeloma. Blood, 113, 5720-5726. https://doi.org/10.1182/blood-2008-08-174946

[16] Basak, G.W., Urbanowska, E., Witkowska, M., Zdunczyk, D., Waszczuk-Gajda, A., Skwierawska, K., Drozd-Sokolowska, J., Skibinska, M., Glazer, M., Madry, K. and Torosian, T. (2010) CXCR4 Inhibitor Plerixafor and G-CSF Allow for an Effective Peripheral Blood Stem Cell Collection in Patients Who Failed Previous Mobilization Attempt. Translational Biomedicine, 1, 2.

[17] Malik, S., Yanovich, S., Rapoport, A., Badros, A., Hardy, N. and Kocoglu, M. (2015) Outcome Comparison of Lymphoma and Myeloma Patients after Autologous Stem Cell Transplantation (ASCT) with Peripheral Blood Stem Cell Mobilization between Plerixafor (P) Mobilized in Poor Mobilizer Patients and Non-Plerixafor Mobilized Patients. Blood, 126, 5507. https://doi.org/10.1182/blood.V126.23.5507.5507 